\title{
Application of PANTERA system for monitoring vibrations induced by blasting works in open pit mining plants and the role of supervisors
}

\author{
Grażyna Dzik*, Adam Mirek
}

State Mining Authority, Katowice, Poland

\begin{abstract}
Measurements of vibrations induced by blasting works in mining plants are one of the possibilities of controlling the operations of open-pit facilities by supervisory authorities. As part of these works, impact of vibrations surveys on buildings within the range of harmful impacts zone of seismic vibrations are carried out to guarantee the safety and protection of their residents. The article presents the possibilities of using digital apparatus for recording and processing vibrations induced by blasting works used during supervisory activities in open-pit mines from 2015 to 2017. Recording and size of events depends on mining conditions and geological structure of the exploited deposit and is closely related to detonation of explosive. The use of dynamic impacts SWD scale against the backdrop of the current norm no PN-B-02170:2016-12 are discussed and examples of assessments of harmfulness of vibrations transmitted by the ground to buildings are presented. It was found that bigger and bigger number of monitoring measurements is performed every year, causes reducing the number of complaints and incriminating letters on mine companies receive in effects of impact of vibrations.
\end{abstract}

Keywords: open pit mines, vibration monitoring, blasting works, ground vibrations, dynamic impact scales SWD

\section{Introduction}

Mining works utilizing explosives can produce harmful effects on buildings and other structures. Recording para-seismic vibrations induced by blasting works in open-pit mining plants using the PANTERA digital vibration recorder is therefore the basic method for mining supervision authorities to reliably measure the parameters of para-seismic vibrations in the aspect of their harmful effects on buildings and other structures situated in the closest vicinity of mining plants. With this, the correct operation of the mining plant, including the blasting works conducted there, are also verified. Hence the idea to create a device, the architecture of which would comprehensively support inspection and control personnel in its operations. One of the most important features of this device is its continuous monitoring and cyclic measurements functionality, which has proven useful in the course of inspection

\footnotetext{
*Corresponding author: g.dzik@wug.gov.pl
} 
works. The device automatically converts digital signal and calculates earth accelerations based on the measurement data and using a third octave filter, and ultimately generates reports presenting the results in SWD (Dynamic Impact Scales), including a full set of information required to identify the event. These features of the device can be used to conduct ongoing monitoring of the safety of seismic works. The complete calculation process does not require complex systemic calculations, and the end result is the earth acceleration value, visualized in SWD scales. What is noteworthy is that the most decisive factors that contribute to the overall effects of blasting works are, firstly: the geological structure of the deposit and its environment, then: the technical condition of protected buildings and structures, the method of transferring vibrations from the groundwork to the building, and, ultimately, the weight of the EC in the borehole or a series of boreholes. These factors influence the result of measurement. However, it should be stressed that the building deterioration process is related to both increased ambient factors and the very structure of the building, and the duration of impact of vibrations on these buildings.

The purpose of the article was to present the possibilities of uses of paraseismic apparatus in the operations of mining supervision uses to identify threats in the movement of open-pit mining plants, and to guarantee the seismic safety of blasting works. In this way, the catalog of control activities was expanded to include measurements of para-seismic vibration parameters in the aspect of their detrimental effect on the environment of mining plants, and a basic analysis and documentation of vibrations recorded, in terms of their effect on protected buildings and structures.

\section{Laws regulating the impact of blasting works in open-pit mining plants}

Control operations often result from the need to minimize the impact of mining works on buildings and structures situated in the vicinity of the mining plant, and involve a determination of the safety conditions pertaining to the environment of blasting works, and documentation of this impact level. The Geological and Mining Law [1] regulates issues related with supervision and control under Article 154 and Article 153 section 1 in the operations of a mining plant extracting minerals from deposits. As regarding blasting works and measurements carried out amid mining operations and related to their safety, all proceedings must conform to the provisions of Appendix 4 to the ordinance of the [9] Minister of Energy of 9 November 2016. This appendix lays down the principles of designating hazard zones around the place where blasting works are performed, and the material expert is authorized to designate the range of the hazard zone: based on rock fragment dispersion, para-seismic vibrations of the rock mass (estimated calculations) and airborne shock wave.

\section{PANTERA Digital Vibration Recorder used for observing the impact of para-seismic vibrations on the environment}

The PANTERA Digital Vibration Recorder is a portable, autonomous vibration and explosion recorder and analyzer, used for observing the impact of para-seismic vibrations on the environment. The instrument is also used to analyze low-frequency ground and building vibrations in areas threatened by para-seismic vibrations induced by human activity - i.e. blasting works. Any vibrations detected are recorded by accelerometers, and then saved in the recorder's memory, from where they are transferred by the user to computer memory, together with the processing software installed. This software is used to archive and process event records according to the Polish standard applicable to assessments of the harmful 
effects of vibrations on buildings according to the effective Dynamic Impact Scale (SWD). The CRD PANTERA system comprises three-component accelerometers ( $\mathrm{x}, \mathrm{y}$ - horizontal components, $\mathrm{z}$ - vertical component) which measure the acceleration of seismic vibrations, a GPS module for synchronizing the time and locating the device, a measurement system and a power supply system. Digital vibration recording is carried out by writing the values of "a" amplitudes in time " $t$ " in the form of binary files saved in the recorder's memory. One of the characteristic features of the device is its automatic spatial orientation and time synchronization with any random time standard. Accelerometers measure the acceleration of vibrations in a range from 1 to $800 \mathrm{~Hz}$, and the operator can configure the device and its parameters to suit the measurement range, the duration of recording and the recording release level. After completing the transfer of detected and recorded vibrations from the device, the operator can perform an amplitude and frequency analysis of the recording, filter signals, and then generate an event measurement report, archive data and, ultimately, assess the impact of vibrations on buildings and structures as per PN-B-02170:1985 [6]. It is noteworthy that measures have been taken to adapt the system to the latest and effective version of PN-B02170:2016-12 [7]. However, these differences do no influence the result of measurement. The PANTERA recording and measurement device has a Calibration Certificate issued by a calibration laboratory (Laboratory of Technical Acoustic, Central Mining Institute) accredited by the Polish Centre for Accreditation, a signatory to EA MLA and ILAC MRA concerning the mutual recognition of calibration certificates.

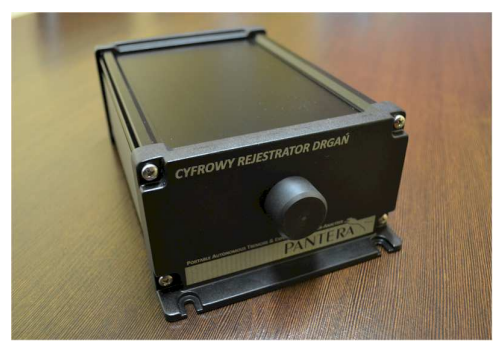

Fig. 1. Digital Vibrations Recorder PANTERA [3].

Inspection and control works generally consist in verifying the safety of blasting works. Instruments recording vibrations caused by para-seismic shocks are used for this purpose. Correlated with data obtained for the blasting works, the records created can be used to verify the measured parameters against true measurements performed in the field. The flexible waves created disperse when the explosion energy is released, posing a threat to mine pits, and, most of all, to the buildings and structures on the surface. Control operations assume continuous observation (monitoring) and cyclic measurements. Permanent, long-term supervision of blasting works carried out by the company provides a holistic image of the rock form processes in place and foundation reactions and their impact on blasting works in the buildings under observation. Vibration recorders are used to assess the threat to buildings and structures caused by para-seismic vibrations. By documenting the impact of vibrations on buildings and structures by generating event reports, this impact can be controlled in a systemic manner. Additionally, a database is created and provides unlimited access for data verification.

\section{Assessment of impact of blasting works on buildings and structures}

Until November 2016, mining plants adhered to PN-B-02170:1985 [6] "Assessment of harmful effects of ground-transferred vibrations on buildings", a standard developed by a 
Krakow University of Technology team headed by Prof. Roman Ciesielski [2]. The standard admitted the application of Dynamic Impact Scales (SWD) in the approximate assessment of vibration impact on buildings. In more than 30 years, sufficient knowledge and experience has been gathered through tests to modify it [10]. The outcome of these works is the amended standard PN-B-02170:2016-12 [7] bearing the same name, which has superseded the 1985 version. What is noteworthy is that one of the most significant amendments is the introduction of SWD for acceleration values, and the withdrawal of displacement scales which have proven redundant due to the type of sensors used. Therefore, acceleration and speed were adopted as the basic values to be recorded. Assessment is currently performed on the basis of the maximum value of the parameter, on third-octave bands. The descriptions of criteria applicable to assessments of vibrations transmitted onto buildings were specified to include SWD - i.e. zone and SWD limit descriptions, as well as descriptions of requirements for dynamic measurements - device installation requirements. In general terms, after recording the vibrations (Fig. 6), performing calculations (Fig. 7) and marking the results on nomograms (Fig. 8), the harmful effects of the vibrations recorded can be identified. In conclusion, the standard is applied to recognize the harmful effects of vibrations on existing buildings, as well as in designing buildings, if the building is expected to be prone to vibrations transmitted by the groundwork.

The criteria and scales used to assess the human-induced effects. SWD consider not only the intensity of vibrations or their frequency, but also the type, structure and dimension of buildings.
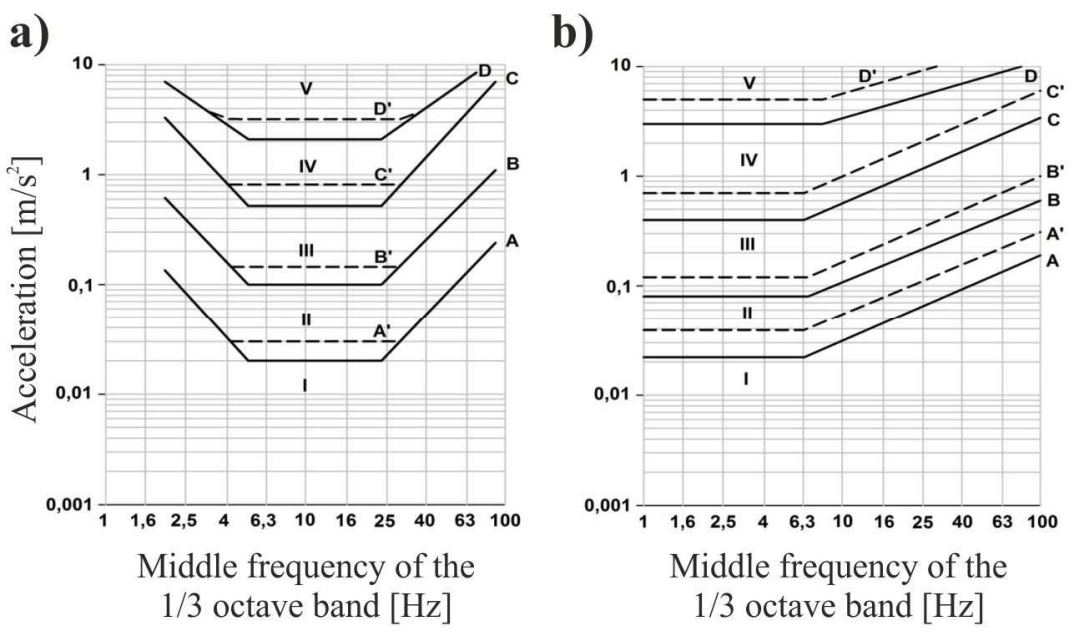

Fig 2. Logarithmic dynamic effect scales in the function of acceleration $\left[\mathrm{ms}^{-2}\right]$ : a) SWD-I and b) SWDII, including descriptions of building vibration impact zones where $\mathrm{x}$ axis - middle frequency of the 1/3-octave band, y axis - maximum vibration acceleration amplitudes in the band (PN-B-02170:201612). Zone I - negligible vibrations, Zone II - harmless vibrations, Zone III - harmful vibrations, Zone IV - high-frequency vibrations, harmful to the building. Boundary lines of the SWD scale for the criteria of fulfilling the condition: A - perceptibility, B - stiffness, C - strength, D - stability. [7].

According to Fig. 2, SWD scales have five zones separated by borderlines which describe the level of harmfulness of vibrations on the buildings. SWD-I includes tight-structured buildings, of small external dimensions in the horizontal projection $(<15 \mathrm{~m})$, one- or twostory, the height of which does not exceed any of the horizontal-projection dimensions. In turn, SWD-II includes buildings up to 5 above-ground stories, the height of which does not exceed the double lowest width of the building, as well as low buildings (up to 2 aboveground stories) which do not fulfill the requirements specified for SWD-I [7]. 
To obtain correct results for the vibration values measured, one needs to know the geological structure of the deposit and the environment, the technical condition of protected buildings, the conditions for the dispersion of waves between the groundwork and the building, and, ultimately, the weight of the explosive in the borehole or its series [10].

\section{Test results and its analysis- impact of vibrations induced by blasting works and their effect on the environment.}

Fig. 3 presents data for individual types of measurements performed in the course of controls implemented in open-pit mining plants relative to half-year time frames (with the exception of 2015, for which data was consolidated). The chart presents the number of various measurements performed in a time frame, i.e. a measurement performed for a residential building and the company building on the ground, a measurement in the harmful vibration zone, and monitoring. Until the end of 2016, the majority of measurements were performed for residential buildings and company buildings. However, following consultations concerning the device and the measurement methodology, measurements have been performed predominantly for residential buildings for a year now. The correctness of this methodology is proven by the mere small number of incriminating letters received by mining authorities or complaints concerning sensations or building damages occurring during or after blasting works carried out by companies. In this respect, we have noticed that, after 2016, following a series of intensive seismic safety inspections in companies conducting blasting works, a trend consisting in reducing the number of measurements has emerged in 2017. These trends generally result from a smaller number of complaints received, broader knowledge of residents of buildings situated in the closest vicinity of mining plants, and broader knowledge of companies themselves, as well as more effective measures taken by inspectors controlling the activity of mining plants.

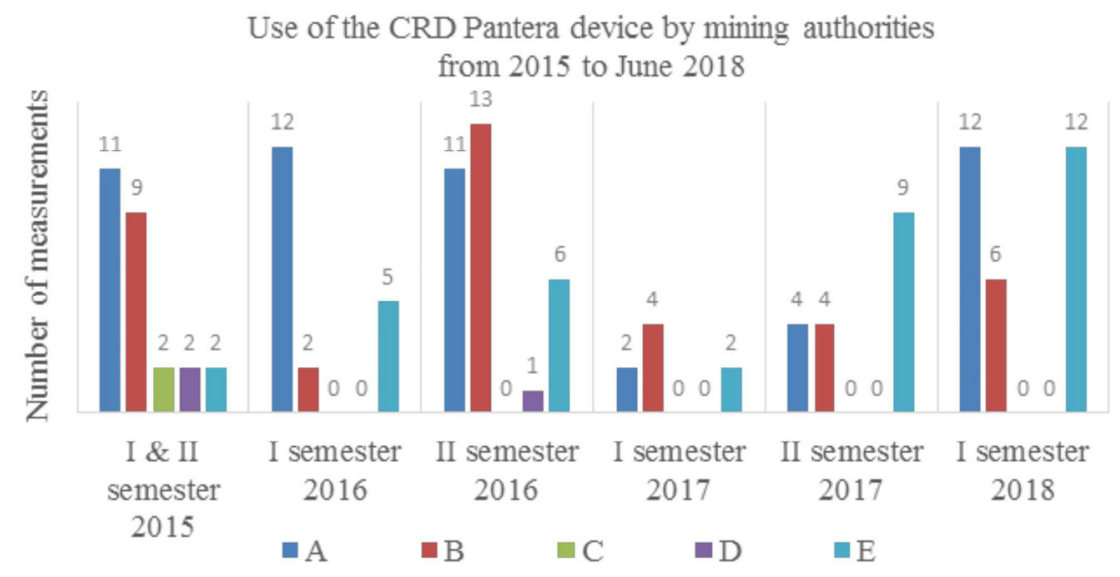

Fig. 3. Types and the number of measurements performed with the use of the PANTERA device by mining authorities from 2015 to June 2018 (A - Measurement on the residential building in connection with a complaint, B - Measurement on the entrepreneur's building in connection with the complaint, $\mathrm{C}$ - Measurement in the zone of harmful vibrations, D - Measurement on the ground, E - Monitoring). 


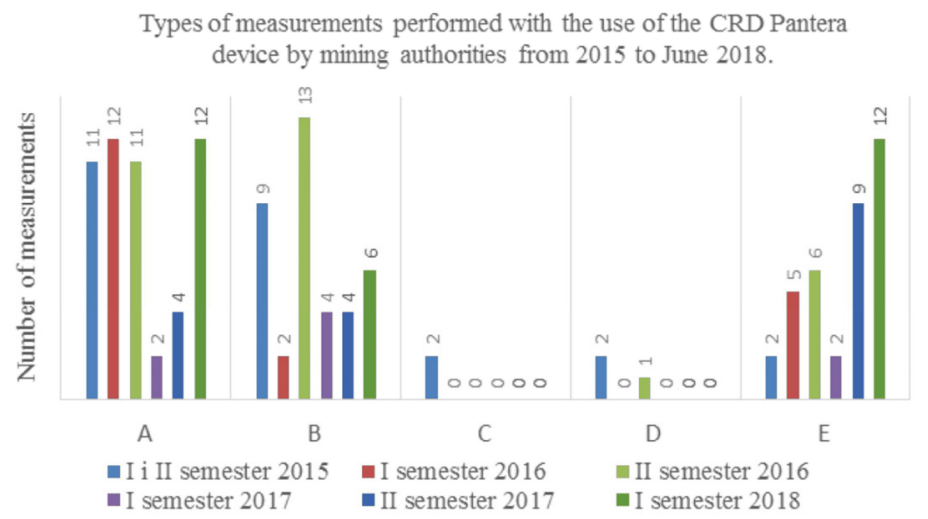

Fig. 4. Types of measurements performed with the use of the PANTERA device by mining authorities from 2015 to June 2018 (A - Measurement on the residential building in connection with a complaint, $\mathrm{B}$ - Measurement on the entrepreneur's building in connection with the complaint, C - Measurement in the zone of harmful vibrations, D - Measurement on the ground, E - Monitoring).

Fig. 4 presents the number of various measurements (performed for a residential building and the company building on the ground, a measurement in the harmful vibration zone, and monitoring) in half-year intervals, proving the legitimacy of measurements taken. Therefore, measurements performed in a residential building or with the company are the largest percentage of measurements carried out as part of supervision activities. According to Fig. 5 , this is a total of $95 \%$ of measurements related to events recorded in open-pit mining plants. $40 \%$ of these measurements taken in 3.5 years were performed applying the monitoring method, using devices installed for a period of 2 weeks up to three months. Returning to Fig. 4. Note that the most measurements taken in the last year were continuous measurements. This practice was accepted not only by inspectors, but also by inquirers who demanded verification if the blasting works would be conducted safely, without effect on their buildings. Literature of the field includes multiple examples of monitoring activities $[4,5,8]$. It is therefore justified to strive to uphold this trend, as information from monitoring measurements is reliable, contrary to single, incidental event measurements which are often taken with the consent of the company. The next two columns contain measurements performed in the harmful vibrations' zone and on the ground, taken as part of tests only.

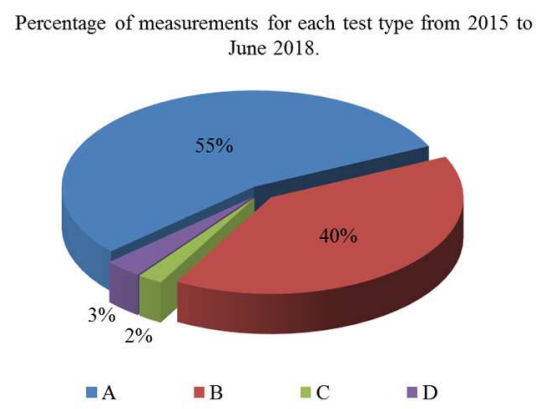

Fig. 5. Percentage of measurements performed for each test type from 2015 to June 2018 (A Measurement on the residential building in connection with a complaint, B - Measurement on the entrepreneur's building in connection with the complaint, $\mathrm{C}$ - Measurement in the zone of harmful vibrations, D - Measurement on the ground). 

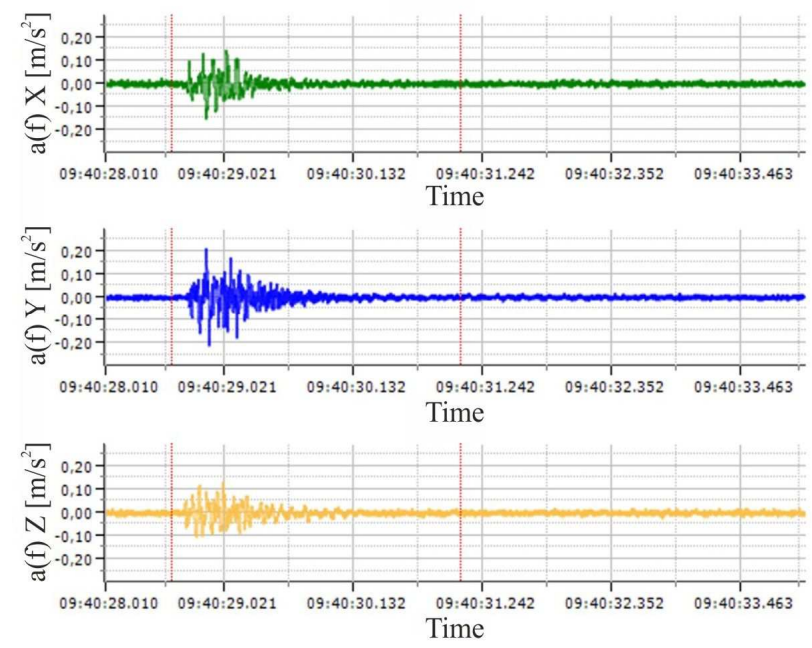

Fig. 6a. Example of seismogram for para-seismic vibrations recorded for event 1 as a result of blasting works involving a total charge of $450 \mathrm{~kg}$, distributed in a system of boreholes. The maximum acceleration at the sampling speed of $1600 \mathrm{~Hz}$ is $0.152 \mathrm{~m} / \mathrm{s}^{2}$ for axis $\mathrm{X}, 0.215 \mathrm{~m} / \mathrm{s}^{2}$ for axis $\mathrm{Y}$, and 0.13 $\mathrm{m} / \mathrm{s}^{2}$ for axis $\mathrm{Z}$.

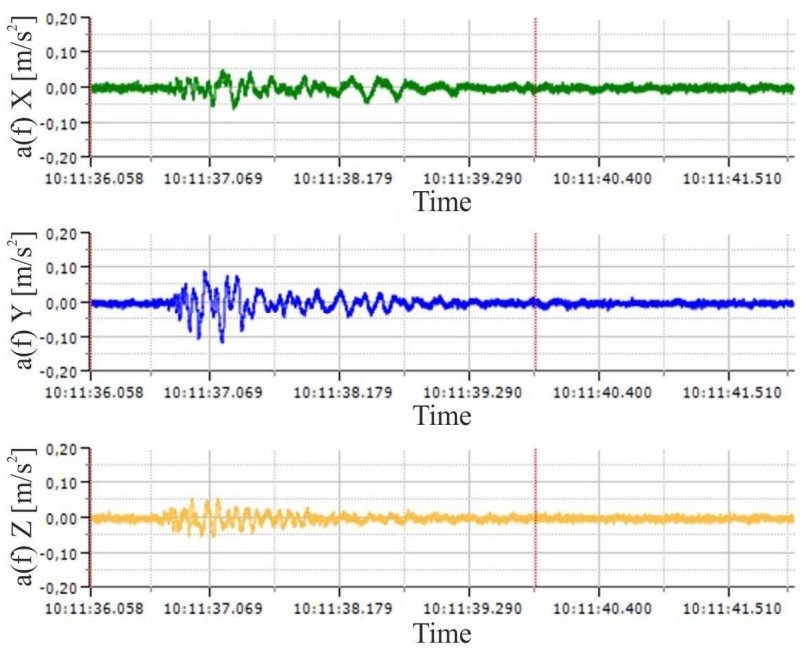

Fig. 6b. Example of seismogram for para-seismic vibrations recorded for event 2 as a result of blasting works involving a total charge of $250 \mathrm{~kg}$, distributed in a series of boreholes. The maximum acceleration at the sampling speed of $1600 \mathrm{~Hz}$ is $0.06 \mathrm{~m} / \mathrm{s}^{2}$ for axis $\mathrm{X}, 0.117 \mathrm{~m} / \mathrm{s}^{2}$ for axis $\mathrm{Y}$, and $0.06 \mathrm{~m} / \mathrm{s}^{2}$ for axis $\mathrm{Z}$.

Fig. 6a and Fig. 6b present an exemplary seismogram for vibrations recorded in the measurement point, i.e. in a residential building. A basic analysis of the seismogram is reduced to determining the maximum values of the measured parameter, i.e. acceleration in this case, compared to the values of vibration frequencies. An analysis applying a thirdoctave filter can be used to precisely assess the effect of vibrations induced by blasting works on buildings situated in the vicinity of the mine (Fig. 7a, Fig. 7b). The assessment is carried out by use of a dynamic impact scale SWD (Fig. 8a, Fig. 8b), where the maximum values of the acceleration amplitude are shown. As a result, an information document - a report is 
generated. For further analysis, the data is subject only to expert judgment. However, as current norm PN-B-02170:2016-12 [7] says, short-term vibrations with parameters fitting in the upper zone, if the given conditions from Table 4, column 3 of the above norm, effects can be attributed to the lower zone, provided that the appropriate conditions are met in the norm.

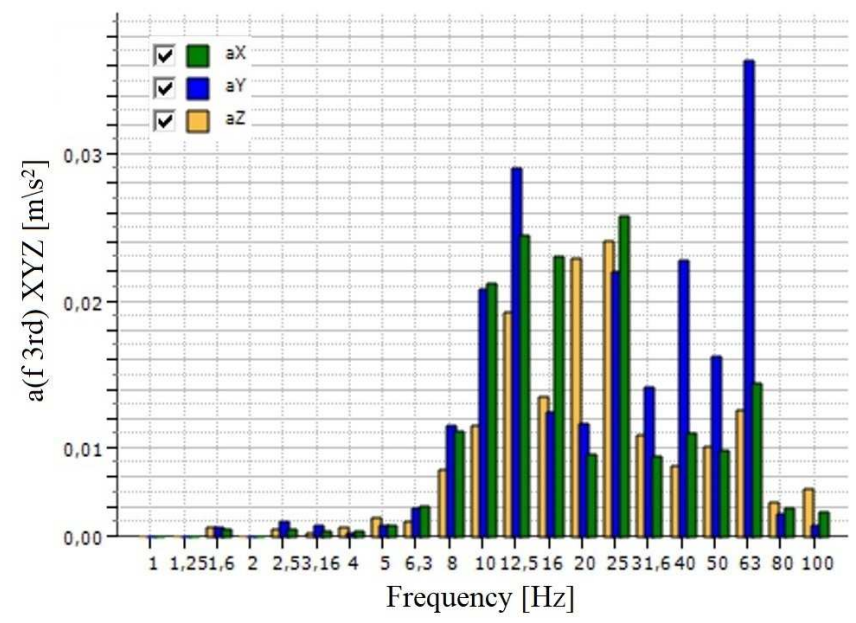

Fig. 7a. Diagram following a third-octave analysis for event 1 , recorded for a residential building (component $\mathrm{X}$ - frequency [Hz], component $\mathrm{Y}$ - acceleration $\left[\mathrm{m} / \mathrm{s}^{2}\right]$ ).

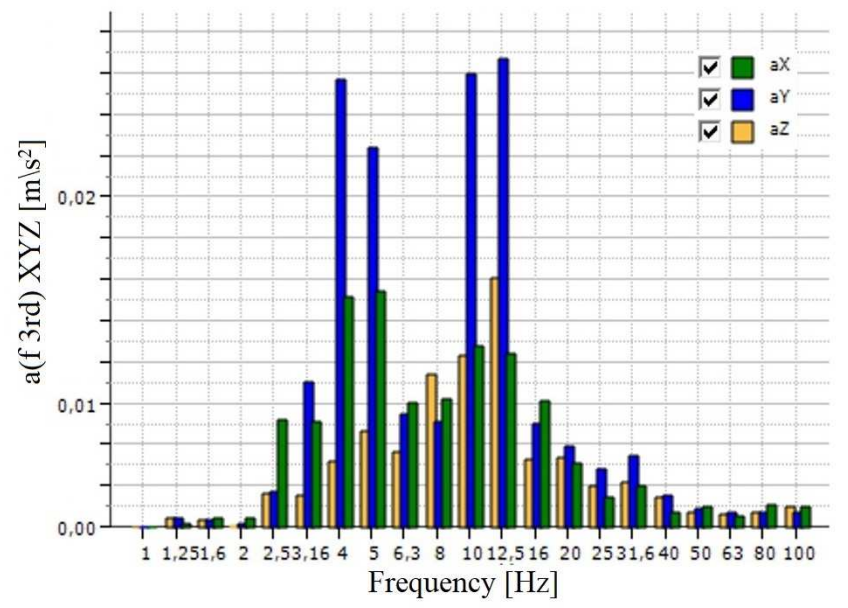

Fig. 7b. Diagram following a third-octave analysis for event 2, recorded for a residential building (component X - frequency $[\mathrm{Hz}]$, component $\mathrm{Y}$ - acceleration $\left[\mathrm{m} / \mathrm{s}^{2}\right]$ ). 


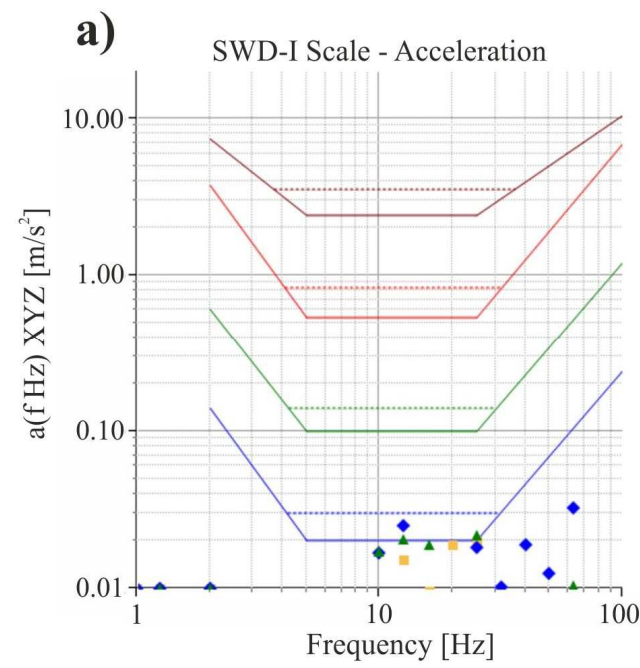

b)

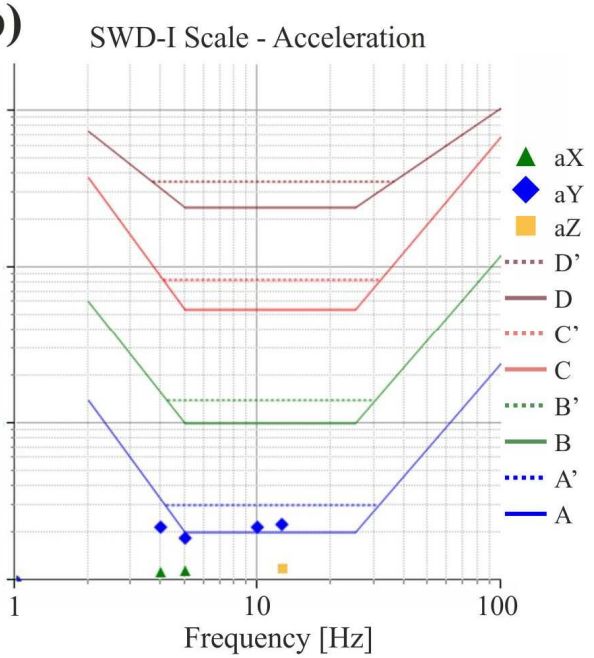

Fig. 8. Diagram of assessment of the impact of vibrations on a building, applying a SWD-I scale for a) event 1 and $b$ ) event 2, indicating maximum acceleration values for individual thirds (component $X$ frequency $[\mathrm{Hz}]$, component $\mathrm{Y}$ - acceleration $\left[\mathrm{m} / \mathrm{s}^{2}\right]$ ).

\section{Conclusions}

Based on the analysis of data and experience gathered from mining authorities, which used the PANTERA device for the last 3.5 years, the following conclusions were presented:

- The digital PANTERA system can be used to conduct ongoing control of the impact of blasting works on buildings situated in the vicinity of open-pit mining plants through monitoring or cyclic measurements. With reference to the standard, it allows to study the harmonic character and long-lasting vibrations, i.e. considering material fatigue.

- As a result of the subsidized enterprise, in 2015-2017, significant improvement in the quality of supervision performed by mining authorities and control of open-pit mining plants was witnessed. This situation contributes to achieving the anticipated effects consisting in better identification of threats to the environment and general safety.

- A data analysis indicated that, between 2015 and June 2018, 55\% of control measurements were carried out in residential buildings, as recommended and according to the idea of para-seismic measurements following official complaints. The remaining $40 \%$ were control measurements carried out company buildings, and 5\% were trial measurements (related to the initial phase of use of the device).

- The clear decrease in the number of complaints and incriminating letters received in the subject of general impact of vibrations on buildings correlates with the largest number of monitoring measurements completed.

Projects titled "Furnishing mining supervision bodies with equipment used to monitor mine operations", subsidized under the National Fund for Environmental Protection and Water Management allowed mining supervision bodies to purchase the CRD PANTERA system used to assess para-seismic vibrations. The PANTERA system was built in accordance with PN-B-02170:1985 [6]. It is currently adapted to the amended version of the standard PN-B02170:2016-12 [7] "Assessment of harmful effects of ground-transferred vibrations on buildings". Many academic centers or licensed material experts from all over the country have switched to the new standard. Therefore, in our pursuit of global standards [10], we try to develop in terms of measurements and new possibilities of controlling the impact of blasting works on buildings. It must be noted, however, that, apart from creating databases, 
measurements performed with the use of para-seismic vibration detection devices used by mining supervision bodies are for the bodies' internal purposes only. This data undergoes expert analyses (performed by material experts) to present evidence in court cases. In conclusion, the most important role of recording the harmful effects of vibrations is the possibility of ordering the company to verify its blasting parameters.

\section{References}

1. Act of 9 June 2011 - Geological and Mining Law (Journal of Laws.2017.2126)

2. R. Ciesielski, Problemy diagnostyczne skutków wstrząsów górniczych na budowle naziemne. (Diagnostic problems of the effects of mining shocks on ground construction) Górnictwo Odkrywkowe 5-6, 13-19 (2004) (in Polish)

3. Operation and Maintenance Documentation for the Digital Data Recorder, instruction manual, EMAG-SERWIS

4. E. Maciąg, Ocena wpływu wstrząsów górniczych na budynki (Assessment of the impact of mining shocks on buildings) [in:] Mat. sympozjum „Warsztaty”, IGSMiE PAN, Krakow, 297-317 (2000) (in Polish)

5. Z. Onderka, R. Biessikirski, J. Sieradzki, J. Winzer, KSMD - System do monitorowania drgań powodowanych robotami strzelniczymi $w$ otoczeniu kopalń odkrywkowych (KSMD - System for monitoring vibrations caused by blasting works in the surroundings of open pit mines), Warsztaty z cyklu ,Zagrożenia naturalne w górnictwie” Mat. Sympozjum,199-211 (2002)

6. PN-B-02170:1985 Assessment of harmful effects of ground-transferred vibrations on buildings.

7. PN-B-02170:2016-12 Assessment of harmful effects of ground-transferred vibrations on buildings

8. J. Pyra, A. Sołtys, J. Winzer, Monitoring drgań jako skuteczne narzędzie do kontrolowania oddziatywania na obiekty (Vibration monitoring as an effective tool for controlling the impact on objects), Mat. Konferencyjne. Technika Strzelnicza w Górnictwie i Budownictwie, Ustroń, 25-27.04.2013, 229-243 (2013)

9. Ordinance of the Minister of Energy of 9 November 2016 on detailed requirements for the storage and use of blasting means and blasting equipment in mining plant operations (Journal of Laws 2017.321)

10. J. Winzer, A. Sołtys, J. Pyra, Oddziaływanie na otoczenie robót z użyciem materiatów wybuchowych (Influence on the surroundings of works with the use of explosives), Wyd. AGH, Krakow (2016) 